\title{
A influência do Centro de Apoio e Promoção da Agroecologia (CAPA) na organização agrícola do Sudoeste do Paraná
}

\author{
La influencia del Centro de Apoyo y Promoción de la Agroecologia \\ (CAPA) en la organización agrícola del Suroeste del Paraná
}

\author{
The influence of "Centro de Apoio e Promoção da Agroecologia" (CAPA) \\ in the agricultural organization of the Paraná Southwest region
}

\author{
Tiago Arcanjo Orben ${ }^{1}$
}

\begin{abstract}
Resumo
Esta pesquisa pretende refletir a atuação do Centro de Apoio e Promoção da Agroecologia (CAPA) na região Sudoeste do Paraná, mais especificamente no município de Verê. Neste munícipio se encontra um dos cinco núcleos que o CAPA possui nos estados do Rio Grande do Sul, Santa Catarina e Paraná. A atenção dada a esta região e a este munícipio se deve por estar relacionada ao assunto abordado em meu projeto de Doutorado em História, o qual procura considerar a estrutura agrária e fundiária da região Sudoeste do Paraná com referência aos levantes sociais ocorridos em outubro de 1957. Neste sentido, a pesquisa questiona a caracterização de pequenas propriedades atribuída a esta região, a qual ganhou destaque na historiografia que pesquisa o tema como resultado da luta social conhecida como Revolta dos Colonos ou Posseiros. Assim, nos primeiros levantamentos constatou-se a significativa atuação, tanto, de cooperativas agrícolas e de crédito que incentivam a produção de monoculturas, quanto, de centros de apoio a produção agroecológica, como o CAPA. Deste modo, utilizando-se da metodologia oral, este trabalho expõe para debate as formas de atuação deste Centro de Apoio a Agroecologia no município de Verê, com atenção especial para seu trabalho junto aos agricultores da região. A partir deste contexto, se sobrepõe para discussão os conceitos de agricultura familiar e pequenas propriedades, enquanto reflexo das relações políticas e sociais verificadas neste espaço.
\end{abstract}

Palavras-Chave: Centro de Apoio e Promoção da Agroecologia; Estrutura Agrária/Fundiária; História Regional; Revolta dos Colonos; Sudoeste do Paraná.

\section{Resumen}

Esta investigación pretende reflexionar sobre la actuación del Centro de Apoyo y Promoción de la Agroecologia (CAPA) en la región Suroeste del Paraná, específicamente en la ciudad de Verê. En esta municipalidad se encuentra uno de los cinco núcleos que lo CAPA posee en los departamentos del Rio Grande del Sur y del Paraná. La atención conduzida a esta región y a esta municipalidad se debe por estar relacionada al asunto planteado en mi proyecto de Doctorado en Historia, el cual busca tener en cuenta la estructura agraria y fundiaria de la región Suroeste del Paraná con relación a las sublevaciones sociales ocurridas en octubre de 1957. En ese sentido, la investigación cuestiona la caracterización de las pequeñas propiedades asignadas a esta región, que ganó atención en la historiografía que investiga el tema como resultado de la lucha social conocida como Revuelta de los Colonos o Poseeros. De esta forma, en los primeros levantamientos se constató la significativa actuación, de cooperativas agrícolas y de préstamos que fomentan la producción de monocultivos y de centros de apoyo a producción agroecologica, como lo CAPA. Así, utilizándose de la metodologia oral, este trabajo expone para discusión las formas de actuación del Centro de Apoyo a Agroecologia en la municipalidad de Verê, con atención especial para su trabajo junto a los agricultores de la

\footnotetext{
${ }^{1}$ Doutorando em História pelo Programa de Pós-Graduação em História - PPGH da Pontifícia Universidade Católica do Rio Grande do Sul-PUCRS; Porto Alegre, Rio Grande do Sul, Brasil. Bolsista Coordenação de Aperfeiçoamento de Pessoal de Nível Superior (CAPES). Trabalho apresentado no I Seminário LatinoAmericano de Estudos em Cultura - SEMLACult, Foz do Iguaçu/PR, Brasil, 2017.Orientador Prof. Dr. Luis Carlos dos Passos Martins. E-mail: tiagoaorben@gmail.com
} 
región. A partir del contexto, se sobreponen para la discusión los conceptos de agricultura familiar y pequeñas propiedades, como reflejo de las relaciones políticas y sociales comprobadas en este espacio.

Palabras claves: Centro de Apoyo y Promoción da Agroecologia; Estructura Agraria/Fundiaria; Historia Regional; Revuelta de los Colonos; Suroeste del Paraná.

\begin{abstract}
In this research I reflect about the actuation of "Centro de Apoio e Promoção da Agroecologia" (CAPA) in the Southwest region of Paraná State, more specifically in municipality of Verê. In this municipality is localized one from five CAPA nucleuses that are distributed in Rio Grande do Sul, Santa Catarina and Paraná states. The attention to Paraná Southwest region is because I am developing my History PhD research there, where I analyze the land ownership and agrarian structure of this region within the context of popular uprisings occurred in October 1957. Accordingly, in the research I question the characteristic of small farms attributed to this region, which is related by historiography as result of social struggle known as Settlers' revolt or Squatters' revolt. Thus, in the first surveys I found a significant actuation of agricultural and credit cooperatives encouraging the monoculture production, as well as of support centers of agroecology production, such as CAPA. Thereby, in this work using oral methodology, I expose for debate the actuation forms of CAPA in Verê, with especial attention to its work together with farmers of region. From this context, the concepts of family farming and small farms are superimposed for discussion as a reflection of the political and social relationships verified in this space.
\end{abstract}

Keywords: Centro de Apoio e Promoção da Agroecologia; Agrarian structure; Regional History; Settlers' Revolt; Southwest region of Paraná.

\title{
1. Introdução
}

Este texto apresenta para discussão algumas questões relacionadas ao aspecto agrário e fundiário em relação à região Sudoeste do Paraná. Assim, procuro refletir a atuação do Centro de Apoio e Promoção da Agroecologia (CAPA) no município de Verê. A escolha desta localidade se deve por desenvolver neste espaço meu projeto de Doutorado em História, o qual procura versar sobre a atribuição de pequenas propriedades que este espaço ganha como fruto de um movimento social ocorrido no ano de 1957, conhecido como Revolta dos colonos ou posseiros. ${ }^{2}$ Alinhado a esta trama o artigo é um dos primeiros resultados das pesquisas realizadas neste espaço, isto é, observou-se a significativa atuação do CAPA enquanto influência nas dinâmicas agrícolas deste município, o que trouxe para discussão as questões que envolvem a caracterização ou a definição de agricultura familiar e pequenas propriedades.

Além disso, é importante frisar que, em relação à agricultura esta região apresenta-se regrada por relações heterogenias, isto é, não conseguimos enquadrar padrões agrícolas que caracterizariam o espaço. Temos uma forte influência de cooperativas agrícolas e de crédito que com um significativo aporte financeiro junto a linhas de crédito do governo federal

\footnotetext{
2 Alguns aspectos deste Levante podem ser observados em minha Dissertação de Mestrado em História: ORBEN, Tiago Arcanjo. A Revolta dos Colonos de 1957, interpretações, apropriações e memórias. Porto Alegre: Dissertação - Mestrado em História, Pontifícia Universidade Católica do Rio Grande do Sul-PUC/RS, 2014.
} 
financiam a produção e implementos agrícolas dos agricultores da região, possibilitando que os mesmos possam produzir monoculturas como, milho e soja, com vistas ao mercado externo. Por outro lado, também pode se verificar nesta região a presença do turismo rural e a produção de alimentos orgânicos, o exemplo do trabalho do CAPA no município de Verê nos mostra isso. Todas essas relações ainda podem ser complementadas com o progressivo aumento nas grandes propriedades agrícolas, ou seja, a caracterização de pequenas propriedades, antes vista na historiografia enquanto fruto do movimento dos colonos de 1957, pode não ser mais tão evidente no espaço em questão.

Desta maneira, este texto esta dividido em três seções, na primeira delas será apresentada uma breve caracterização do CAPA e seu foco de atuação no município em questão, ao mesmo tempo também procuro esclarecer a metodologia usada no trabalho e os objetivos propostos, neste momento será inserida a discussão em torno das caracterizações de pequenas propriedades e agricultura familiar, vistas como essenciais para a compressão da pesquisa em desenvolvimento. Cabe salientar que pretende-se neste ponto destacar a perspectiva do CAPA em relação a esta questão, isso será feito por meio da entrevista realizada com Jhony Luchmann coordenador do CAPA no município de Verê.

Em um segundo momento serão analisados outros aspectos que Luchmann salienta em relação à organização agrária e fundiária do Sudoeste do Paraná e de que maneira o CAPA desempenha suas funções com vistas a esta conjuntura. Neste sentido, serão elencados aspectos relacionados a concentração fundiária do espaço, refletindo em que medida este aspecto relaciona-se ao financiamento agrícola - através de políticas públicas.

Por fim serão apresentadas algumas conclusões, com a intenção de esclarecer a abrangência do trabalho e sua contribuição para as pesquisas relacionadas a história agrária brasileira. Com ênfase para aquelas que dialoguem com os conceitos de pequenas propriedades, agricultura familiar e agroecologia.

\section{A atuação do CAPA no munícipio de Verê}

O CAPA, de acordo com as informações fornecidas em sua página on line, é uma organização da sociedade civil vinculada à Igreja Evangélica de Confissão Luterana no Brasil, foi criada em 1978 e iniciou "suas atividades em 15 de junho de 1979, na cidade de Santa Rosa (RS), com o nome de Centro de Aconselhamento ao Pequeno Agricultor". Consta em suas prerrogativas que o órgão foi criado no momento em que pequenos agricultores e agricultoras estavam sendo expulsos do campo pela chamada "Revolução Verde", a qual pautava a produção agrícola em grande escala através de meios mecanizados e com o uso de 
agrotóxicos. Neste momento, o CAPA se apresenta enquanto uma opção economicamente sustentável para o pequeno homem do campo, oferecendo alternativas para sua permanência no meio rural. (CENTRO DE APOIO E PROMOÇÃO DA AGROECOLOGIA, 2017).

A entrevista oral feita com Jhony Luchmann, ${ }^{3}$ apresenta alguns aspectos sobre a criação do CAPA e de que maneira inicia sua atuação na região sul do Brasil, destacando que na década de 1970 "historicamente foi o maior período de êxodo rural da história do Brasil" e é neste contexto que o órgão foi criado, conforme esclarece:

E ai também entra um pouco desta questão da agroecologia, lá na década de [19]70 era a agricultura alternativa, então o Capa frente ao êxodo rural e a Revolução Verde tava propondo realizar, praticar uma agricultura alternativa ao que estava sendo implantado pelo pacote tecnológico, então era agricultura alternativa, e ai desde o início o Capa sempre trouxe uma alternativa a esse pacotão ai, para os agricultores não ficarem, as famílias não ficarem reféns desse modelo, pra ter uma alternativa e nasceu com esse objetivo, pra viabilizar eles em pequenas áreas de terra, pra eles ter uma condição de viver bem de ter uma renda, consegui se inserir na sociedade também, dignamente, assim tem toda a questão social e a gente caminhou pra focar nesse trabalho de dá essa condição de vida adequada pras famílias. E ai desde o início a gente vem buscando alternativas, todo o contexto social do final da década de [19]70 pra 80, 90 e as políticas públicas que foram iniciando a partir dos anos 2000 e a gente foi inserindo as cooperativas, os públicos dentro desse[...], dessas políticas que foram surgindo (LUCHMANN, 2017, p.05).

Luchmann nos apresenta o contexto de criação do CAPA, em paralelo ao que era apresentado à agricultura brasileira nas décadas de 1970, 80 e 90, com destaque para a Agroecologia enquanto alternativa ao modelo de agricultura proposto pela Revolução Verde. Estas questões estão relacionadas ao modelo de modernização da agricultura enquanto política econômica, proposta apresentada pelo Estado brasileiro e que via nas "ideias oriundas da Revolução Verde" uma "expectativa de superação do subdesenvolvimento através de transformações no setor agropecuário" (FLEISCHFRESSER, 1988, p.12).

Neste sentido, conseguimos notar em que medida o ideal de modernização da agricultura estava alinhado as ideias propagadas pela Revolução Verde. Para Vanessa Fleischfresser o setor agrícola era visto como "uma barreira ao crescimento econômico, cuja transposição ocorreria com a introdução de técnicas novas de produção, basicamente químicas, de sementes apropriadas a elas e de mecanização" (FLEISCHFRESSER, 1988, p.12). Essa conjuntura fica caracterizada pela inserção do pacote tecnológico, que visava a modernização da agricultura, dos meios de produção e de suas técnicas, com o objetivo de

\footnotetext{
3 Jhony Luchmann possui Mestrado em Agronomia e Graduação em Tecnologia em Horticultura, trabalha no CAPA desde 2011.
} 
produzir em larga escala, com vistas ao abastecimento do mercado interno, além de incrementar as exportações.

De acordo com Luchmann é para fazer frente a essas políticas, que expropriavam grande parcela de produtores rurais do campo brasileiro, que o CAPA se apresenta como alternativa. Colocando-se enquanto opção para as pequenas e médias famílias, no momento em que historicamente, no Brasil, ocorre um dos maiores fluxos migratórios do campo para cidade.

Esta conjuntura sobrepõe a agricultura aos padrões do capital industrial, isso significa que o setor agrícola passa a ficar dependente das tecnologias provenientes da indústria, ao mesmo tempo em que aumentam as desigualdades sociais, conforme esclarece Fleischfresser:

Como consequência desse tipo de modernização, as desigualdades socioeconômicas entre os produtores se acentuam, porque se antes já não dispunham de condições homogêneas de produção, com a introdução de técnicas produtivas externas ao meio rural as diferenças se intensificam (FLEISCHFRESSER, 1988, p.12).

Soma-se a estes aspectos o tamanho das propriedades, enquanto para os grandes proprietários a modernização apresentava-se enquanto um interessante viés para a ampliação da produção e da área de plantio, para os pequenos e médios agricultores era uma barreira, sobretudo, para aqueles que possuíam propriedades em terrenos declivosos ou com baixa fertilidade do solo. Enquanto resultado disso, uma significativa parcela de produtores que não conseguem se adaptar a essas condições acabam abandonando o meio rural, ao passo em que aumenta a concentração de terra e o enriquecimento de uma pequena parcela de produtores.

A não adaptação destes pequenos e médios agricultores que vendem suas propriedades e migram para os centros urbanos, acontece principalmente ligada a "uma certa obrigatoriedade" do uso da tecnologia entre os produtores mercantis. Isso acontece porque o mercado intermediário e consumidor absorve o discurso modernizador e procura uma padronização nos produtos agrícolas - tamanho, peso e qualidade - desvalorizando aqueles que não se enquadrem neste modelo.

Conforme se evidência, é em oposição a estes modelos de produção e de técnica agrícola que o CAPA se apresenta, conforme destacou Luchmann, principalmente frente ao êxodo rural e a Revolução Verde. Neste sentido, o CAPA inicia sua trajetória inicialmente no Rio Grande do Sul, posteriormente expande sua atuação para os estados de Santa Catarina e do Paraná. No Paraná, além do núcleo Verê também assessora agricultores na região Oeste do Estado, com núcleo no município de Marechal Cândido Rondon. 
No município de Verê o CAPA foi criado no ano de 1997 e tinha como propósito atuar em "prol da agricultura familiar e camponesa de base ecológica", enquanto núcleo visava fortalecer este segmento na região Sudoeste do Paraná. Neste sentido, está entre suas premissas a produção associativa, solidária e agroecológica, com a intenção de valorizar a agricultura de base familiar e incentivar a preservação do meio ambiente.

Em relação à atuação na região Sudoeste Luchmann destaca alguns elementos sobre a abrangência do CAPA:

\begin{abstract}
Na verdade, hoje nós estamos aqui fixos no Verê, enquanto escritório e sede, mas a atuação ela é por meio de assessoria, então a gente presta serviço, assessora alguns municípios, na verdade hoje nós não temos nenhum técnico fora daqui, então todos estão aqui. Agora, alguns momentos é possível, por exemplo, você ter um técnico que está mais distante aqui, por exemplo, uma região mais pra fronteira, como se fosse Capanema alguma coisa a gente teria condições de ter um técnico específico trabalhando naquela região, que viria esporadicamente pra cá, então se divide dessa forma, poderia se dividir, no caso hoje nesse momento não, hoje a equipe toda está presente aqui e daqui sai distribuindo, fazendo atividades na microrregião (LUCHMANN, 2017, p.04).
\end{abstract}

Neste trecho Luchmann esclarece alguns elementos em relação à forma de atuação do CAPA e sua abrangência no Sudoeste do Paraná. Neste sentido, cabe salientar em um primeiro momento que o trabalho desenvolvido pelo centro é de assessoria, isso significa que, prestam assistência técnica aos colonos da região, sobretudo, para aqueles interessados em implantar um modelo de produção agroecológico, além é claro de assessorar aqueles que já estão inseridos neste modelo de produção.

Luchmann também esclareceu na entrevista que a função essencial do CAPA é prestar assistência aos colonos inseridos ou interessados na produção agroecológica, isso significa que, não compram a produção, tampouco vendem, o centro incentiva meios dos colonos se organizarem em cooperativas ou associações para vender sua produção, ao mesmo tempo em que ajuda aqueles que procuram uma certificação para seus produtos, principalmente para os que já estão inseridos neste meio a mais tempo.

Em relação à abrangência de atuação do CAPA no Sudoeste do Paraná, Luchmann esclarece que eles não possuem nenhum técnico fora do município de Verê, por outro lado, isso não significa que os técnicos do núcleo não possam atender colonos em municípios mais distantes, como na região mais próxima da fronteira com a Argentina. Além destes elementos também cabe salientar que o entrevistado destaca que os núcleos de Verê e Marechal Cândido Rondon são os mais recentes na trajetória do CAPA, ou seja, completam neste ano 20 anos de atuação no Estado do Paraná, sendo os últimos criados na região Sul do Brasil. 
Conforme se evidencia o trabalho tem como fonte primária as orais, trabalhar com a metodologia oral apresenta inúmeras potencialidades ao pesquisador. Neste sentido, para que tenhamos consciência de sua utilização é importante elencar alguns aspectos teóricos e metodológicos que são extremamente importantes para quem tem nas fontes orais sua matéria prima. Verena Alberti ao trabalhar a relação estabelecida entre o entrevistado e o entrevistador destaca que:

Tanto um quanto o outro têm determinadas ideias sobre seu interlocutor e tentam desencadear determinadas ações: seja fazer com que o outro fale sobre sua experiência (o caso do entrevistador), seja fazer com que o outro entenda o relato de tal forma que modifique suas próprias convicções enquanto pesquisador (o caso do entrevistado) (ALBERTI, 2004, p.35).

É nesta relação de diálogo que ocorre a produção da fonte oral e isso nos mostra que não se trata de uma produção neutra, que minimize a presença do entrevistador e do entrevistado, ao se dar por meio de um diálogo cada um dos sujeitos envolvidos na entrevista cria determinadas expectativas, sobre o que contar e o que ouvir. Nesta relação não podemos esquecer que produzir uma fonte oral "é resíduo de uma ação específica" de "interpretar o passado". Evidentemente que, conforme alerta Alberti, não se trata apenas de uma construção a partir do passado, mas sim as "ações de constituição de memórias - as ações que tanto o entrevistado quanto o entrevistador pretendem estar desencadeando ao construir o passado de uma forma e não de outra" (ALBERTI, 2004, p.35).

Além disso, ao produzir uma fonte oral nos colocamos em uma posição delicada, e isso, tem a ver com a noção de neutralidade que muitos pesquisadores almejam ao lidar com esta fonte. Alistair Thomson ao abordar alguns dos desafios para se pensar a história oral fora do mundo ocidental, nos apresenta algumas provocações extremamente pertinentes para refletirmos seu uso. Neste sentido, ao ponderar a perspectiva internacional da história oral, destaca que para essa metodologia firmar-se enquanto referência no campo da história ou nas ciências humanas e sociais, precisa ser pensada sem receita, ou seja, indica que não existe uma maneira certa ou um segredo em se fazer história oral:

[...] a entrevista é uma relação que se insere em práticas culturais particulares e que é informada por relações e sistemas de comunicação específicos. Em outras palavras, não existe uma única "maneira certa" de entrevistar, e a maneira que o "bom senso" indica como "certa" para membros da elite branca do sexo masculino pode ser completamente inadequada em outros contextos culturais (THOMSON, 2000, p.48). 
Talvez o maior desafio aqui proposto é fazer com que as pessoas falem com seus "próprios termos" e não enquanto representantes ou influenciados por determinados valores que podem lhes parecer caro no momento da entrevista. Essa talvez seja a maior barreira a ser superada na entrevista apresentada neste artigo, digo isso porque em primeiro lugar, o entrevistado fala em nome de um determinado órgão e isso pode ser determinante para que apresente um discurso "pronto", que corrobore com os preceitos defendidos pela instituição a qual representa.

Por outro lado, em última instância, estamos interessados no discurso da instituição, já que exploramos a influência do CAPA na organização agrícola do Sudoeste do Paraná. Nesta conjuntura a questão se inverte, em que medida a formação de Luchmann e sua militância para com a causa agroecológica não ira influenciar no desenvolver de seu depoimento sobre a instituição. Visualizamos assim, um campo a ser explorado e que precisa ser considerado ao lidarmos com esta fonte, no momento da entrevista tive essa preocupação e mesmo com um breve roteiro em mãos, constantemente me preocupava com tais flutuações que a entrevista oral pode apresentar.

Desta forma, as palavras de Thomson soam como acalentadoras, ao indicar que não podemos nos propor produzir uma fonte oral a partir de uma "maneira certa", ao considerar que toda entrevista está inserida "em práticas culturais particulares e que é informada por relações e sistemas de comunicação específicos" (THOMSON, 2000, p.48). Evidentemente que não consegui explorar todos os meandros da atuação do CAPA na região em questão, ao mesmo tempo em que possivelmente a experiência de Luchmann e sua militância tenha prevalecido em alguns momentos do depoimento. Por outro lado, são os contextos apresentados pelo entrevistado que representam, sob a perspectiva do CAPA, a organização agrária e fundiária do Sudoeste do Paraná.

Assim, com consciência das relações que pautam a produção do conhecimento histórico por meio da fonte oral, este trabalho tem como objetivo primordial refletir as formas de ação do CAPA na região Sudoeste do Paraná no que se refere a sua influência na organização agrícola deste espaço.

\subsection{Agricultura familiar e pequenas propriedades}

No trabalho desenvolvido no Doutorado em História, ao pensar a estrutura agrária e fundiária de pequenas propriedades, que boa parte da literatura que pesquisa a região a atribui, sobrepõe-se a conceitualização de agricultura familiar. Isso acontece em grande medida em razão da relação que é feita deste conceito com as pequenas propriedades. Todavia, deve-se 
ter certo cuidado na utilização do termo, pois existem, nos dias atuais, não só no Sudoeste do Paraná, mas em nível nacional, grupos que consideram a utilização do termo "pequenos" ou “pequenas" como pejorativo. Isto é, que observam nesta expressão uma redução deste modelo de propriedades.

Entretanto, a região estudada tem um contexto singular. Existem proprietários que possuem propriedades pautadas em uma agricultura familiar orgânica e que aderem a esta ideia de que não são pequenos, mesmo possuindo um terreno com poucos hectares, ao mesmo tempo em que existem aqueles que admitem serem pequenos e que praticam uma agricultura capitalista, com o plantio de monoculturas como soja e milho. Estes agricultores são intermediados pelas cooperativas agrícolas e de crédito, que, por meio de linhas de crédito, financiam suas produções e implementos agrícolas com recursos do governo federal, inserindo esses agricultores nas lógicas capitalistas de produção e mercado, mesmo possuindo uma propriedade considerada pequena.

É pensando no cuidado que é necessário ter com os termos agricultura familiar e pequena propriedade, em uma região com diferentes realidades, que achamos necessário ponderar alguns aspectos historiográficos em relação a eles. Tais considerações possibilitaram ainda uma compreensão mais apurada da realidade apresentada nas entrevistas.

De acordo com o que expõe Delma Pessanha Neves (2005), pensar a conceitualização de agricultura familiar não é tarefa simples ou fácil. Para a autora, o termo tem uma conotação primordial que "se referia a segmentos de produtores (modernos) integrados ao mercado pela especialização e sob uso intensificado de instrumentos de trabalho concebidos segundo a lógica da produção industrial”. Ou seja, como categoria, estes agricultores estariam atrelados à lógica de interdependência entre a "agricultura e a indústria". Todavia, Neves (2005) alerta que o termo com essa conotação não foi incorporado pelos pesquisadores brasileiros, sendo este modelo de interconexão agricultura e indústria, mais caracterizado no Brasil como “agricultores integrados ou tecnificados" (NEVES, 2005, p.23).

É no esteio desta discussão que o termo se redimensiona junto aos pesquisadores brasileiros que passam a encarrar:

A proposição da agricultura familiar como novo termo de apelação, de mobilização política e de enquadramento social consagrou então a construção de novos modelos de desenvolvimento econômico, capazes de orientar a organização de unidades produtivas politicamente requeridas como sustentáveis. Emerge então, desse processo, a construção do agricultor familiar como sujeito de direitos (NEVES, 2005, p.23). 
A conotação adotada no Brasil passa a ser em grande medida de "mobilização política" e "enquadramento social", voltada para as unidades produtivas ou as propriedades indicadas como "sustentáveis". Esse processo acaba dando "visibilidade ao projeto de valorização de agricultores e trabalhadores rurais precarizados", que sofriam justamente a interferência da ação entre indústria e agricultura, processo visto no Brasil como acirrador de "exclusos e expropriações diversas" (NEVES, 2005, p.23).

Visto sob esta ótica, é possível que notamos não só diferentes significados para o termo agricultura familiar, mas, também, em que contexto é apresentado à realidade brasileira e redimensionado por pesquisadores. Junto a isso, sobre as múltiplas significações do termo, Neves pondera:

A agricultura familiar, no debate político e sindical, corresponde à agregação de um amplo e diferenciado conjunto de produtores, cuja atividade produtiva e gestão do estabelecimento tomam por base a vinculação dos membros da família. Essa é a condição fundamental de sua distinção frente aos empresários agropecuários, gestores de fatores de produção cuja exploração se assenta no trabalho assalariado (NEVES, 2005, p.24).

Em linhas gerais, tem-se a vinculação da agricultura familiar como atividade diferenciada - em comparação aos empresários agropecuários e gestores de produção e exploração do trabalho assalariado - enquanto gestão do estabelecimento ou da propriedade com vinculação aos membros da família. Desta maneira, a agricultura familiar brasileira estaria ligada essencialmente ao trabalho em propriedades que envolvam a família. Essa posição pode ser evidenciada em contexto recente junto às políticas públicas criadas para os grupos identificados como agricultores familiares.

A título de exemplo, cita-se a Lei 11.326/2006 que estabelece "os conceitos, princípios e instrumentos destinados à formulação das políticas públicas direcionadas à Agricultura Familiar e Empreendimentos Familiares Rurais" (PRESIDÊNCIA DA REPÚBLICA: CASA CIVIL: SUBCHEFIA PARA ASSUNTOS JURÍDICOS, 2015), que determina em seu artigo $3^{\circ}$ as seguintes prerrogativas:

I - não detenha a qualquer título, área superior a quatro módulos fiscais; II - utilize mão-de-obra predominantemente da própria família em suas atividades econômicas; III - tenha percentual mínimo originado das atividades de seu estabelecimento; IV dirija o estabelecimento com sua família, com auxílio eventual de terceiros (PRESIDÊNCIA DA REPÚBLICA: CASA CIVIL: SUBCHEFIA PARA ASSUNTOS JURÍDICOS, 2015). 
Gonçalves Neto e Reis (2014) sinalizam que o mais significativo neste artigo é o que determina o item IV, o qual estabelece que a agricultura familiar se caracterize como estabelecimento que seja dirigido pela família e com o "auxílio eventual de terceiros" (GONÇALVES NETO; REIS, 2014, p.90). Essas prerrogativas trazem para junto da agricultura familiar alguns benefícios para que teoricamente se valorize a produção, seus meios e os sujeitos nela envolvidos. Entretanto, na região aqui privilegiada, nem sempre a conceitualização de agricultura familiar e pequenas propriedades envolve predominantemente a mão de obra familiar em seus meios de produção.

Conforme já argumentado acima, com a inserção das cooperativas agrícolas e de crédito, boa parte dos agricultores que são considerados da agricultura familiar produz para o mercado externo e envolvem poucos membros da família. Isso levando em consideração que se trata de uma produção altamente mecanizada, que não necessita de muitas pessoas no processo produtivo.

Por outro lado, a presença e atuação do CAPA apresenta justamente a diversidade de relações que podemos verificar neste espaço, que mesmo possuindo uma forte atuação de cooperativas agrícolas e de crédito, tem na produção de produtos orgânicos uma significativa rede de agricultores.

A partir deste panorama, é possível observar tanto a diversidade que essa conceitualização pode ter, quanto à dificuldade de aplicarmos a caracterização de agricultura familiar em diferentes realidades brasileiras, como, por exemplo, no Sudoeste paranaense, no qual relações heterogêneas na organização da produção agrícola mostram-se presente. Ao mesmo tempo, essa análise demonstra o quanto este conceito é maleável e depende da ação política ou de políticas públicas, sendo determinado, em muitos casos, por relações de poder, que o redimensionam conforme a política pública que atenda.

\section{Financiamento agrícola e concentração fundiária}

Este item pretende explorar em que medida o financiamento agrícola influencia na estrutura agrária e fundiária da região estudada, ao mesmo tempo, também será dado destaque a aspectos relacionados a concentração da propriedade da terra, sobretudo, enquanto reflexo dos processos que pautam o financiamento agrícola no Brasil.

Antes de refletir esse cenário serão apresentados alguns pontos mais gerais sobre a atuação do CAPA no município de Verê e na região Sudoeste do Paraná, tais aspectos são elencados para indicar em que medida o referido centro de aconselhamento e promoção da agroecologia consegue ter êxito em suas políticas. Neste sentido, em um primeiro momento 
Luchmann procura expor um breve histórico de mudanças no nome do CAPA, indicando que anteriormente o Centro de Apoio e Promoção da Agroecologia era chamado de "Centro de Apoio ao Pequeno Agricultor", assim, graças aos debates promovidos em relação a esta questão decidiu-se excluir o termo "pequeno agricultor", principalmente em razão do debate que existia em torno deste termo, conforme esclarece:

Porque agora a gente entendia que teoricamente assim, dizer que pequeno agricultor é um termo um pouco pejorativo, então havia um debate bem significativo que a gente promovia muitas vezes, que não eram pequenos agricultores, que eram sim grandes produtores de alimentos de comida [...] (LUCHMANN, 2017, p.05).

Na opinião de Luchmann estes agricultores têm uma "importância social gigantesca" e o nome do CAPA não comtemplava essa importância, ao mesmo tempo em que os reduzia, ao lhes taxas como pequenos. Conforme ficou evidente no item anterior existe toda uma discussão em relação a essa questão, ao considerar que também existem aqueles agricultores que se identificam como pequenos, mas que muitas vezes produzem em suas propriedades monoculturas, essa realidade é encontrada com muita facilidade em diferentes regiões do Brasil, inclusive no Sudoeste do Paraná.

Além destas questões, Luchmann procurou destacar em seu depoimento a abrangência de atuação do centro na região, conforme elenca:

[...] a gente tem em torno ai de 10, 12 municípios que a gente tem alguma incidência de fato, não por meio às vezes de uma assessoria técnica, mas a gente tá beneficiando por meio de certificação, a gente tá viabilizando para que as famílias consigam certificar sua unidade produtiva pra vender o alimento como orgânico, então às vezes uma assessoria mais indireta por meio de uma associação, cooperativa, agricultores que tão, são sócios da cooperativa aqui, que a gente tá aportando, assessorando e beneficiados pela comercialização. Então assim, a gente considera que a gente tem uma atuação microrregional destes municípios (LUCHMANN, 2017, p.07).

Luchmann destaca a incidência do CAPA na região, que gira em torno de 10 a 12 municípios, considerando que o Sudoeste do Paraná possui hoje 42 municípios podemos dizer que a atuação deste centro incide em cerca de $25 \%$ dos municípios da região. Conforme o próprio entrevistado infere: "poderia ser muito mais, porque tem demanda de trabalho", por outro lado, essa demanda fica reprimida pela falta de aporte financeiro, isso porque, $70 \%$ dos recursos financeiros que mantém a atuação do CAPA são basicamente provenientes de um fundo alemão, Luchmann esclarece esses aspectos da seguinte forma: 
Então assim, nós somos uma ONG financiada pela agência de cooperação internacional chamada: 'Pão para o Mundo' 'Brotfür die Welt' em alemão e são projetos trienal, três anos né, e hoje basicamente $70 \%$ vem de lá, então teria que ter uma contrapartida local pra gente conseguir aporta esse trabalho pra mais (LUCHMANN, 2017, p.07).

Caso o centro conseguisse atuar em outros municípios da região seria possível não só incentivar a produção de alimentos orgânicos e a agroecologia, mas também, meios de comercialização dessa produção em associações ou cooperativas. O entrevistado destaca que no município de Verê existe a CoperVereda, uma associação de produtores rurais que é assessorada pelo CAPA.

Todavia, para que essa realidade possa ser transformada depende do empenho das prefeituras da região, Luchmann infere que "historicamente o Sudoeste [do Paraná] não é uma região de municípios muito bem financeiramente" e isso faz com que as prefeituras prefiram "incha a sua folha de pagamento com funcionários contratados e não investi muitas vezes em áreas que seriam estratégicas para o município" (LUCHMANN, 2017, p.07). É possível identificar neste ponto um aspecto interessante da organização econômica dos municípios da região, isso porque a maioria dos municípios não possuem grandes receitas ao mesmo tempo em que grande parte da pequena receita que arrecadam fica com o pagamento dos funcionários públicos da prefeitura.

Além disso, Luchmann destaca que muitos municípios "investem 30, 40\% do valor" de seu orçamento "em saúde na secretária de saúde e são municípios campeões de uso de agrotóxicos". O próprio entrevistado enfatiza que não desautoriza o investimento em saúde, mas sim, a relação irônica e sem lógica em se investir tanto em saúde e ao mesmo tempo ter municípios na região campeões no uso de agrotóxicos:

Então tem uma relação bem irônica, você investe todo quase o recurso que a prefeitura tem na saúde, mas na agricultura o orçamento é $2,3 \%, 5 \%$, então qual que é a política de fato pra propor alguma coisa pra reduzir o índice de utilização de agrotóxicos, uma coisa assim que fica assim fora de lógica (LUCHMANN, 2017, p.07).

No entendimento do entrevistado essas questões estão relacionadas, o não investimento em um modelo de agricultura agroecológico ou um pequeno investimento, de "2, 3\%, 5\%", acaba dando margem para o avanço do agronegócio, que tem enquanto premissa em seus processos de produção o uso intensivo de agrotóxicos. Ao mesmo tempo, Luchmann questiona: "por que é que tem tantos índices de câncer? Por que é que tem tantos índices de depressão no meio rural"? (LUCHMANN, 2017, p.07). Isto é, no seu entendimento tais 
questões estão relacionadas, os municípios acabam tendo que investir mais em saúde por não priorizar a qualidade de vida das pessoas em relação à produção agrícola e a alimentação. Com um orçamento minúsculo para essas áreas a produção de alimentos agroecológicos não ganha espaço na agricultura do município e isso está totalmente ligado ao aumento da concentração da propriedade da terra e ao maior investimento em saúde.

É exatamente sobre estes aspectos que dialogaremos em seguida, sobretudo em relação à concentração da propriedade da terra, está realidade é cada vez mais visualizada na região estudada, com destaque tanto, para o aumento das propriedades dos grandes produtores, como, no número de arrendamento da terra. Neste caso, muitos médios proprietários que plantam até 10 alqueires, por possuírem implementos agrícolas, conseguem aumentar a área de plantio através do arrendamento, principalmente das terras pertencentes aos pequenos produtores. Luchmann nos aponta algumas questões relacionadas a isso:

\footnotetext{
É, o que eu estou percebendo assim é que há uma concentração de terra, não propriamente de compra, mas de arrendamento, isso a gente tem, algumas famílias que estão ai com uma área bem significativa de plantio, mas que não são proprietários, são arrendatários, isso de certa forma é uma concentração, mas hoje a expressão da distribuição no nosso território aqui é o agronegócio! Então ele que fala mais alto, então ele que domina toda a questão de terra aqui, de plantio e ai assim, todo o sistema tá desenhado pra atender as demandas dele e ai a gente tem observado algumas situações que, as famílias estão vendendo as propriedades, as menores, às vezes assim o cara tem 10,15 alqueires, um agricultor grande né! Consideravelmente grande e ai tem um cara do lado, um vizinho que tem dois, três alqueires, mas uma terra boa! Faz uma proposta gigantesca e ai compra, compra mesmo, porque às vezes faz umas loucuras de oferta 2.500 mil [aproximadamente 160 mil reais por alqueire] e quinhentos sacos de soja, então se a terra é boa (LUCHMANN, 2017, p.14).
}

Os pequenos proprietários que muitas vezes acabam arrendando sua terra ou vendendo são, na maioria dos casos, agricultores que não conseguem se adequar a modelo de produção agronegociante, ao mesmo tempo em que não são absorvidos pela produção de alimentos orgânicos. Por vezes falta de assistência técnica, financiamento ou mesmo incredulidade neste modo de produção, por acreditar que esse modelo de agricultura "não dá dinheiro". Além disso, os pontos destacados por Luchmann contradizem a tese de que a região Sudoeste do Paraná tem uma estrutura fundiária diferenciada com vistas aos levantes de 1957.

Ao observar a realidade que nos foi exposta por meio da entrevista de Luchmann, podemos constatar de que maneira o agronegócio tem avançado neste espaço, assim, o fato de existirem um número significativo de pequenas e médias propriedades não tem significado um entrave para o desenvolvimento deste modo de produção agrícola. Isso se reflete na concentração da propriedade da terra, ou seja, no aumento do número de grandes 
proprietários, "tem famílias ai que tem, são grandes produtores já, pega ai famílias que tem 300, 400 alqueires de terra, passa de 1.000 hectares" (LUCHMANN, 2017, p.14).

Além disso, outro ponto que deve ser considerado e que está totalmente relacionado com a concentração da propriedade da terra é o financiamento agrícola. Atualmente o governo federal por meio do Banco Nacional do Desenvolvimento (BNDES) disponibiliza linhas de crédito para os pequenos e médios agricultores, principalmente através do Programa Nacional de Fortalecimento da Agricultura Familiar (Pronaf) e do Pronafinho para microcrédito, além é claro de diversas outras linhas. Existem também linhas de financiamento para investimentos em implementos agrícolas ou mesmo na modernização da propriedade, novos equipamentos, estufas, resfriadores de leite, etc.

Todos estes benefícios são direcionados para os pequenos e médios agricultores, desde que se enquadram nas premissas do governo em relação ao crédito agrícola. Assim, observando sob essa premissa teoricamente ocorreria uma valorização dos pequenos agricultores, além de incrementos na propriedade e possibilidade de maior diversidade na produção. Todavia, não é exatamente essa a realidade encontrada em várias regiões do Brasil e em muitos casos no Sudoeste do Paraná, na entrevista de Luchmann, graças à proximidade que o entrevistado tem com estes processos é possível perceber em que medida o crédito agrícola concedido pelo governo federal acaba financiamento muito mais o agronegócio do que uma experiência familiar de produção agroecológica, conforme esclarece:

\footnotetext{
Esse é um tema bem delicado, porque assim, algumas cooperativas ai nasceram com o objetivo de fato de atender a agricultura propriamente bem familiar e hoje tão financiando a rodo o agronegócio. Então esse tema é bem delicado, porque muitas vezes as famílias que a gente acompanha precisavam de um investimento de 4 mil reais, 5 mil reais, que ia ajudar muito a propriedade! Às vezes a compra de um micro trator usado, às vezes a construção de duas ou três estufas, às vezes a implantação de um sistema de irrigação, às vezes é adquirir mudas de frutas, e ai assim, a burocracia que o banco coloca pra fazer o investimento é muito grande e ai esses 4, 5 mil reais, 10 mil reais, não compensa pra eles, daí assim, você financia uma lavoura ai de, faz um investimento pra um soja, um milho ai que financia 100, 150, 200 mil ai é uma questão lógica de capital, então tem dificuldades sim! (LUCHMANN, 2017, p.12, 13).
}

Em primeiro lugar é importante destacar que Luchmann trata o tema como "delicado", ou seja, o entrevistado enquanto entendedor da realidade agrícola da região, ao tratar o tema do financiamento agrícola como delicado nos indica que existem inúmeros problemas em relação a isso, sobretudo para pequenos ou microcréditos. O que Luchmann destaca é que a burocracia apresentada aos bancos para se fazer um financiamento, tanto de custeio, quanto de investimento, é muito grande, assim, não é muito vantajoso para as cooperativas de crédito - 
Cresol, Sicredi, Sicoob ou mesmo o Banco do Brasil - fazer o processo burocrático para um financiamento de até 15 mil reais. Recurso qual seria essencial para um pequeno agricultor.

Além disso, o entrevistado questiona o fato de muitas destas cooperativas de crédito terem se desenvolvido nas últimas décadas graças a estas linhas de crédito para a agricultura familiar, ao passo que acabam financiando "a rodo" o agronegócio. Esse processo acontece porque a partir do momento em que os pequenos e médios agricultores não conseguem microcréditos para modernizar suas propriedades, acabam cedendo as pressões do agronegócio, isto é, vendem ou arrendam suas propriedades para aqueles que conseguem produzir em maior escala e que ao mesmo tempo financiam valores maiores, de "100, 150, 200 mil”. Assim, conforme elenca Luchmann, “é uma questão lógica de capital”, aqueles que possuem mais recursos acabam obtendo maior sucesso na agricultura, neste caso, com o modelo agronegociante, que preza pelo plantio de monoculturas, sobretudo soja, milho e trigo enquanto cultura de inverno.

Evidentemente que essas questões não estão restritas a apenas estes elementos, existe todo um círculo econômico que se retroalimenta com a manutenção deste modelo de produção agrícola, tanto, revendedoras de máquinas agrícolas de grande porte, quanto, vendedores de insumos e agrotóxicos. Sabe-se que todas estas relações pautam questões econômicas e movimentam diferentes setores da econômica local e regional, por outro lado, também exclui deste processo aquele que não é conveniente a lógica de reprodução social do capital. Assim, tanto para o estado capitalista, quanto para as relações de reprodução da vida econômica em nível local, é mais interessante o modelo de agricultura agronegociante, que mesmo não sendo o ideal para todos, é o ideal no aspecto econômico.

\section{Considerações finais}

A partir das considerações apresentadas, este trabalho pretende contribuir para as discussões relacionadas a produção de produtos orgânicos ou a agroecologia. Para tanto, utilizando-se do método de história oral foi privilegiado o trabalho do CAPA, com destaque para a região Sudoeste do Paraná e o munícipio de Verê, local onde esta entidade possui um dos seus núcleos de atuação junto aos agricultores.

Além destas questões, o trabalho procura destacar a heterogeneidades de relações que podem ser verificadas na estrutura agrária e fundiária da região Sudoeste do Paraná, com ênfase para, em que medida podem ser verificadas diferentes relações econômicas e sociais ligadas a agricultura neste espaço. Neste sentido, constatou que o CAPA exerce significativa 
influência na organização agrícola do espaço em destaque, sobretudo enquanto assessoria técnica para os agricultores interessados em uma produção orgânica ou agroecológica.

Todavia, conforme se evidenciou o CAPA encontra muitas dificuldades para expandir sua abrangência no espaço em questão, tanto no aspecto ideológico, muitos não creem neste modelo enquanto lucrativo em suas atividades agrícolas, quanto, na questão econômica, em relação a falta de incentivos dos municípios. Ao mesmo tempo em que os recursos disponibilizados pelo BNDES - que teoricamente poderiam beneficiar esse grupo de pequenos e médios agricultores, acabam sendo direcionados - através das cooperativas de crédito - para o financiamento de um modelo de agricultura alinhada ao agronegócio.

Infelizmente esta conjuntura é encontrada com certa facilidade em diferentes regiões do Brasil, em especial na região centro sul, que concentra grande número de cooperativas agrícolas e de crédito, que ao reproduzirem e incentivar este modelo de agricultura agronegociante - junto médio agricultores, acaba consolidando e aumentando as desigualdades sociais e a contratação da propriedade da terra. Conforme ficou evidente na entrevista de Luchmann, existe demanda para o desenvolvimento de práticas agroecológicas na agricultura brasileira, por outro lado, é necessário mais incentivo financeiro dos municípios em nível local e, principalmente maior força de vontade das cooperativas de crédito, para que a expansão deste modelo de agricultura possa realmente acontecer.

Além disso, em relação à estrutura fundiária da região, cabe elencar a significativa retração do modelo de pequenas propriedades, que se em algum momento foi fruto do movimento social de 1957, tem perdido cada vez mais essas características graças ao avanço do agronegócio que, ao mesmo tempo em que diminui o número de pequenas propriedades, concentra a posse da terra.

\section{Referências}

ALBERTI, Verena. Ouvir contar: textos em história oral. Rio de Janeiro: Editora FGV, 2014.

FLEISCFRESSER, Vanessa. Modernização tecnológica da agricultura: contrastes regionais e diferenciação social no Paraná da década de 70. Curitiba: Livraria do Chain: CONCITEC: IPARDES, 1988.

GOMES, Iria Zononi. 1957: A Revolta dos Posseiros. Curitiba: Criar Edições, 1986.

GONÇALVES NETO, João da Cruz; REIS, Luá Cristine Siqueira. Produção de alimentos: agricultura familiar x cultura de exportação no Brasil, sob a perspectiva da sustentabilidade. Revista Brasileira de Políticas Públicas. Brasília, v. 4, n. 1, 2014, p. 89-98. 
NEVES, Delma Pessanha. Agricultura familiar. In: MOTTA, Márcia. (org.) Dicionário da terra. Rio de Janeiro: Civilização Brasileira, 2005.

ORBEN, Tiago Arcanjo. A Revolta dos Colonos de 1957, interpretações, apropriações e memórias. Dissertação (Mestrado em História), Porto Alegre, Pontifícia Universidade Católica do Rio Grande do Sul - PUC/RS, 2014.

THOMSON, Alistair. Aos cinquenta anos: uma perspectiva internacional da história oral. In: ALBERTI, Verena, FERNANDES, Tania Maria, FERREIRA, Marieta de Moraes. (Orgs.) História oral: desafios para o século XXI. Rio de Janeiro: Editora Fiocruz, 2000.

\section{Fontes}

CENTRO DE APOIO E PROMOÇÃO DA AGROECOLOGIA - CAPA: <http://capa.org.br/> Acesso em 21 de abril de 2017.

LUCHMANN, Jhony. Entrevista concedida a Tiago A. Orben. Perímetro urbano do município de Verê/PR: 02 de junho de 2017, duração: 01h 22min. 26segs.

PRESIDÊNCIA DA REPÚBLICA: CASA CIVIL: SUBCHEFIA PARA ASSUNTOS JURÍDICOS: LEI: 11.326/2006: <http://www.planalto.gov.br/ccivil_03/_ato20042006/2006/lei/111326.htm> Acesso em 09 de novembro de 2015. 